\title{
CRÓNICA CONSTITUCIONAL DEL AÑO 2002
}

\author{
MIGUEL ÁNGEL PRESNO LINERA \\ Profesor Titular de Derecho Constitucional \\ Universidad de Oviedo
}


SUMARIO

UNIÓN EUROPEA Y RELACIONES INTERNACIONALES.- PARTIDOS POLITICOS Y PROCESOS ELECTORALES. - ÓRGANOS CONSTITUCIONALES Y AUTONÓMICOS.- ORGA-

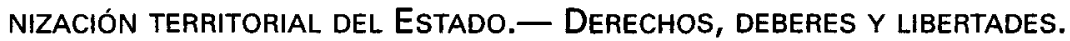




\title{
CRÓNICA CONSTITUCIONAL DEL AÑO 2002
}

\author{
POR \\ MIGUEL ÁNGEL PRESNO LINERA \\ Profesor Titular de Derecho Constitucional \\ Universidad de Oviedo
}

En esta Crónica, como ya se dijo en la entrega correspondiente al año 2001, se ha optado por realizar una presentación de carácter temático y no exclusivamente cronológica, por entender que así se puede ofrecer una panóramica más completa de los sucesos acaecidos, muchos de los cuales no se han concretado en un momento temporal único, sino que han tenido un desarrollo progresivo a lo largo de los doce meses examinados e, incluso, se extienden a años sucesivos. Como resulta obvio, dentro de cada sección o apartado sí se produce una ordenación temporal.

Los grandes bloques temáticos se refieren a la Unión Europea y las relaciones internacionales, los partidos políticos y los procesos electorales, a los órganos constitucionales y autonómicos, a la organización territorial del Estado y, por último, a los derechos, deberes y libertades de los ciudadanos.

Con la finalidad de dotar a este trabajo de más contenido, se han introducido como novedades respecto de la Crónica del año 2001 las referencias a las normas de las Comunidades Autonómas que incidan de alguna manera en alguno de los bloques temáticos analizados. 


\section{UNIÓN EUROPEA Y RELACIONES INTERNACIONALES}

En estas materias hay que aludir, en primer término, a los trabajos preparatorios del Proyecto de Constitución Europea, objetivo al que trata de servir la "Convención Europea», para cuya Presidencia el Consejo Europeo nombró a Valéry Giscard d'Estaing, y a Giuliano Amato $y$ Jean-Luc Dehaene Vicepresidentes.

La Convención reúne a las principales partes interesadas en el debate sobre el futuro de la Unión 1 . Además de su Presidente y de sus dos Vicepresidentes, consta de 15 representantes de los Jefes de Estado o de Gobierno de los Estados miembros (1 por Estado miembro); 13 representantes de los Jefes de Estado o de Gobierno de los paises candidatos a la adhesión (1 por país candidato); 30 representantes de los Parlamentos nacionales de los Estados miembros (2 por Estado miembrol; 26 representantes de los Parlamentos nacionales de los Estados candidatos (2 por país candidato); 16 representantes miembros del Parlamento Europeo; 2 representantes de la Comisión Europea. Además, cada uno de los miembros titulares de la Convención tiene un suplente. El Comité Económico y Social (tres representantes), el Comité de las Regiones (seis representantes), los interlocutores sociales (tres representantes) y el Defensor del Pueblo Europeo asisten en calidad de observadores. La Declaración de Laeken establece que los países candidatos a la adhesión participarán plenamente en las deliberaciones, si bien no podrán impedir el consenso que pudiera alcanzarse entre los Estados miembros.

Los trabajos de la Convención reciben el impulso de un Praesidium, integrado por el Presidente de la Convención, los dos Vicepresidentes, dos representantes de los miembros del Parlamento Europeo, los dos representantes de la Comisión, dos representantes de los Parlamentos nacionales y los representantes de los Gobiernos español, danés y griego (los países que ejercen la Presidencia de la Unión Europea durante la Convención). El Praesidium invita a todas sus reuniones a un miembro de la Convención designado por los representantes de los países candidatos. La sesión inaugural se celebró el 28 de febrero de 2002 y en la de 28 de octubre se presentó el Anteproyecto de Tratado Constitucional, que consta de tres partes: la primera sobre

1 Para obtener más información puede consultarse la página web del Consejo para el Debate sobre el Futuro de la Unión europea

(http://www.futuro.europa.es). 
las disposiciones que definen la arquitectura institucional; la segunda sobre las políticas y acciones de la Unión y la tercera contiene las disposiciones finales y de continuidad jurídica habituales en este tipo de acto constitucional2.

Los días 21 y 22 de junio se celebró en Sevilla la "Cumbre European, cuyas conclusiones se centraron en los cambios en la política de asilo e inmigración, la reforma del Consejo Europeo, la ampliación de la Unión, el crecimiento económico y la lucha contra el terrorismo.

En la "Cumbre Europea" de Copenhague ( 13 y 14 de diciembre) se cerraron las negociaciones de adhesión de 10 Estados: Letonia, Lituania, Estonia, Polonia, Hungría, República Checa, Eslovaquia, Eslovenia, Malta y Chipre.

En lo que respecta a las modificaciones experimentadas en la legislación española para ajustarla a las normas comunitarias, han de mencionarse:

la Ley $10 / 2002$, de 29 de abril, por la que se modifica la Ley $11 / 1986$, de 29 de abril, de Patentes, para la incorporación al derecho español de la Directiva 98/44/CE, del Parlamento Europeo y del Consejo, de 6 de julio, relativa a la protección jurídica de las invenciones biotecnológicas (BOE n. ${ }^{\circ} 103$, de 30 de abril); la Ley 39/2002, de 28 de octu-

2 La primera parte, que recoge las disposiciones fundamentales contendría un preámbulo y a continuación definiría: Qué es la Unión (su definición y su naturaleza jurídica); por qué los Estados miembros han decidido reunirse (cuáles son los valores y los objetivos que los unen); qué significa ser un ciudadano de la Unión; y cuáles son los derechos fundamentales de la Unión; cuáles son las competencias de la Unión; se precisará que la Unión sólo tiene las competencias que se le atribuyan; se afirmarán de manera precisa los principios de subsidiariedad y de proporcionalidad; cuáles son las instituciones de la Unión; de qué manera se organiza la ejecución de la actuación de la Unión, en aras de la sencillez, transparencia y eficacia; cuáles son los principios de la vida democrática de la Unión; la financiación de la Unión; la acción exterior de la Unión; las relaciones entre la Unión y su entorno cercano; el concepto de que la Unión está abierta a todos los Estados europeos que respeten sus valores y derechos fundamentales y acepten sus normas. La segunda parte del Tratado, sobre las políticas y acciones de la Unión, recogería un gran número de cláusulas de los Tratados actuales. Se introducirían modificaciones técnicas en los artículos relativos a las políticas de la Unión, que serían necesarias para poner en consonancia esta segunda parte con la primera. La tercera parte contendría disposiciones finales y de continuidad jurídica.

Las disposiciones finales deberían contener las cláusulas que garanticen la continuidad jurídica en relación con la Comunidad y la Unión Europea. Puede consultarse el texto íntegro en la página:

http://register.consilium.eu.int/pdf/es/02/cv00/00378es2.pdf. 
bre, de transposición al ordenamiento jurídico español de diversas directivas comunitarias en materia de protección de los intereses de los consumidores y usuarios (BOE $n .{ }^{\circ} 259$, de 29 de octubre) y la Ley 47/2002, de 19 de diciembre, de reforma de la Ley 7/1996, de 15 de enero, de Ordenación del Comercio Minorista, para la transposición al ordenamiento jurídico español de la Directiva $97 / 7 / \mathrm{CE}$, en materia de contratos a distancia, y para la adaptación de la Ley a diversas Directivas comunitarias (BOE $n .^{\circ} 304$, de 20 de diciembre).

En lo que tiene que ver con la actividad normativa derivada de las relaciones internacionales de España, hay que hacer mención:

al Instrumento de Adhesión de España al Acuerdo sobre Privilegios e Inmunidades del Tribunal Internacional del Derecho del Mar, hecho en Nueva York el 23 de mayo de 1997 (BOE n. ${ }^{\circ}$ 15, de 17 de enero); al Instrumento de ratificación del protocolo facultativo de la Convención sobre los Derechos del Niño, relativo a la venta de niños, la prostitución infantil y la utilización de niños en la pornografía, hecho en Nueva York el 25 de mayo de 2000 (BOE n. ${ }^{\circ} 27$, de 31 de enero); al Instrumento de ratificación del Protocolo $n .^{\circ} 2$ al Convenio Europeo para la Prevención de la Tortura y de las Penas o Tratos Inhumanos y Degradantes, hecho en Estrasburgo el 4 de noviembre de 1993 (BOE n. ${ }^{\circ} 35$ de 9 de febrero); al Instrumento de ratificación del protocolo facultativo de la Convención sobre los Derechos del Niño, sobre la participación de niños en conflictos armados, hecho en Nueva York el 25 de mayo de 2000 (BOE n. ${ }^{\circ}$ 92, de 17 de abrill; al Protocolo de enmienda al Convenio europeo sobre la Televisión Transfronteriza hecho en Estrasburgo el 9 de septiembre de 1998 (BOE n. ${ }^{\circ}$ 92, de 17 de abril); al Instrumento de ratificación del Convenio Internacional para la Represión de la financiación del terrorismo, hecho en Nueva York el 9 de diciembre de 1999 (BOE n. 123 , de 23 de mayo); al Instrumento de adhesión de España al Convenio de Unidroit sobre bienes culturales robados o exportados ilegalmente, hecho en Roma el 24 de junio de 1995 (BOE n. 248 , de 16 de octubre); al Instrumento de aprobación por parte de España del anexo $\mathrm{V}$ del Protocolo al Tratado Antártico sobre Protección del Medio Ambiente, hecho en Bonn el 18 de octubre de 1991 (BOE $n .^{\circ} 148$, de 16 de octubre), y al Instrumento de ratificación del Estatuto de Roma de la Corte Penal Internacional, hecho en Roma el 17 de julio de 1998 (BOE n. ${ }^{\circ} 126$, de 27 de mayo). El 11 de abril se superó el número mínimo de ratificaciones (60 países) para la entrada en vigor de la Corte Penal Internacional.

Por su parte, el Tribunal Europeo de Derechos Humanos condenó al Estado español a resultas de la demanda interpuesta por el ex coronel del Cesid, D. Juan Alberto Perote, por vulneración de su derecho a un juicio justo. El Tribunal apreció una vulneración del art. 6.1 del Convenio Europeo de Derechos Humanos como consecuencia de 
que el Presidente y el Ponente del Tribunal Militar que le juzgó habían intervenido en numerosos actos previos de instrucción. El fallo se limita a constatar la vulneración del Tratado.

\section{PARTIDOS POLÍTICOS Y PROCESOS ELECTORALES}

En lo que a los partidos políticos hace referencia, lo más significativo que ocurrió el pasado año fue, como es bien conocido, la aprobación de la Ley Orgánica 6/2002, de 27 de junio, de Partidos Políticos (BOE n. ${ }^{\circ} 154$, de 28 de junio), contra la que presentó Recurso de Inconstitucionalidad el Gobierno Vasco, admitido por el Alto Tribunal por Providencia de 15 de octubre.

Como proclama la propia Exposición de Motivos, las mayores novedades de la Ley se contienen en el capítulo II, en el que se concretan los criterios básicos para garantizar el mandato constitucional sobre el funcionamiento democrático de los partidos. Así, se prevé un órgano asambleario de carácter participativo general al que se reservan las competencias más relevantes en la vida del partido, se establece el sufragio libre y secreto como medio ordinario de cobertura de los puestos directivos, se prevé la censura democrática de los mismos, se reconocen algunos derechos básicos, como participar en la elección y ser elegibles en los órganos, o los de información de las actividades, de la situación económica y de las personas que configuran los órganos directivos, y se determinan algunas reglas básicas de funcionamiento $y$ régimen de las reuniones de los órganos colegiados.

En el artículo 9 se dispone que un partido será declarado ilegal cuando su actividad vulnere los principios democráticos, particularmente cuando con la misma persiga deteriorar o destruir el régimen de libertades o imposibilitar o eliminar el sistema democrático. mediante alguna de las siguientes conductas, realizadas de forma reiterada y grave: vulnerar sistemáticamente las libertades y derechos fundamentales, promoviendo, justificando o exculpando los atentados contra la vida o la integridad de las personas, o la exclusión o persecución de personas por razón de su ideología, religión o creencias, nacionalidad, raza, sexo u orientación sexual; fomentar, propiciar o legitimar la violencia como método para la consecución de objetivos políticos o para hacer desaparecer las condiciones precisas para el ejercicio de la democracia, del pluralismo y de las libertades políticas; complementar y apoyar políticamente la acción de organizaciones terroristas para la consecución de sus fines de subvertir el orden constitucional o alterar gravemente la paz pública, tratando de someter a un clima de terror a los poderes públicos, a determinadas personas o grupos de la sociedad o a la población en general, o con- 
tribuir a multiplicar los efectos de la violencia terrorista y del miedo y la intimidación generada por la misma.

Se entenderá que concurren las citadas circunstancias cuando se produzca la repetición o acumulación de una serie de conductas: Dar apoyo político expreso o tácito al terrorismo,...; acompañar la acción de la violencia con programas y actuaciones que fomentan una cultura de enfrentamiento $y$ confrontación civil ligada a la actividad de los terroristas, ...; incluir regularmente en sus órganos directivos o en sus listas electorales personas condenadas por delitos de terrorismo que no hayan rechazado públicamente los fines y los medios terroristas...

El texto establece que sea la Sala especial del Tribunal Supremo prevista en el artículo 61 de la Ley Orgánica del Poder Judicial el órgano competente para poder disolver un partido político, cuando éste desarrolle graves conductas contrarias a la Constitución. Para ello se establece un proceso judicial específico, preferente, en única instancia, que sólo podrán instar el Ministerio Fiscal y el Gobierno, por sí o a instancia del Congreso de los Diputados o del Senado. La sentencia dictada por la Sala especial no será objeto de recurso alguno, sin perjuicio, en su caso, del amparo ante el Tribunal Constitucional, y será ejecutiva desde el momento de su notificación.

El artículo 12 detalla los efectos de la disolución judicial de un partido político. Tras la notificación de la sentencia, se procederá al cese inmediato de toda su actividad y se presumirá fraudulenta y, por tanto, no podrá prosperar la constitución de una formación que continúe o suceda al declarado ilegal y disuelto.

La regulación se completa con varias disposiciones complementarias que, entre otras cosas, permiten ajustar a la nueva Ley las previsiones de la Ley Orgánica del Poder Judicial (adicional primera, para que la Sala especial del Tribunal Supremo entienda de estos casos), y de la Ley Orgánica del Régimen Electoral General (adicional segunda, para precisar que tampoco cabe el fraude de constituir, en los períodos electorales, agrupaciones de electores que vengan a suceder, de facto, a un partido político disuelto o suspendido). En lo que atañe a la competencia de la Sala especial, la Ley acumula la garantía de que sea ésta la competente para conocer y resolver en los casos de fraude, bien en su condición de Sala sentenciadora (apartados 2 y 3 del artículo 12), bien por la llamada expresa que ahora se introduce en la legislación electoral para la resolución de recursos contra la proclamación o no de agrupaciones de electores (disposición adicional segunda), bien por la previsión del apartado 2 de la disposición transitoria única, sobre la sucesión de partidos para soslayar los efectos de la presente Ley.

En aplicación de esta Ley, el Congreso de los Diputados decidió instar al Gobierno la ilegalización de Herri Batasuna-Euskal HerritarrokBatasuna, en un pleno de 26 de agosto, con los votos a favor de 295 Diputados: Ios del Partido Popular, Partido Socialista, Coalición Cana- 
ria y Partido Andalucista; votaron en contra 10 Diputados: del Partido Nacionalista Vasco, Ezquerra Republicana de Catalunya, Eusko Alkartasuna e Iniciativa per Catalunya; se abstuvieron 29: los de Convergéncia i Uniò, Izquierda Unida, Bloque Nacionalista Galego y Chunta Aragonesista.

Ese mismo día 26 de agosto, el juez Baltasar Garzón dictó un Auto en el que acordó la suspensión cautelar durante tres años de todas las actividades de Herri Batasuna-Euskal Herritarrok-Batasuna. En aplicación de este Auto, el 16 de septiembre el Parlamento de Navarra acordó la disolución del Grupo Parlamentario de Batasuna y la integración de sus siete miembros en el Grupo Mixto.

En otro orden de cosas, han de mencionarse las diversas Cuestiones de Inconstitucionalidad planteadas por la Sección Primera de la Sala de lo Contencioso-Administrativo de la Audiencia Nacional (BOE n. ${ }^{\circ} 121$, de 21 de mayo) en relación con el apartado primero de la disposición adicional vigésima tercera, "pago de subvenciones a partidos políticos», de la Ley 24/2001, de 27 de diciembre, de medidas fiscales, administrativas y del orden social.

El 16 de diciembre, y ante la Comisión Mixta para las Relaciones con el Tribunal de Cuentas, se presentó el Informe de Fiscalización de la contabilidad de los partidos políticos correspondiente al Ejercicio de 1999, así como el Informe Complementario relativo a la Fiscalización de las Elecciones al Parlamento de Cataluña.

El informe de fiscalización fue aprobado por el Pleno del Tribunal el 25 de julio de 2002. Se trata del primer informe elaborado tras la aprobación en octubre de 2001 de la moción relativa a la modificación de la normativa sobre financiación y fiscalización de los partidos políticos (véase el BOE $n .^{\circ} 200$, de 21 de agosto). El Informe presenta, junto a los resultados de las comprobaciones habituales efectuadas sobre los estados financieros de 18 formaciones políticas, un informe complementario elaborado a solicitud del Parlamento de Cataluña, en el que el Tribunal formula propuestas de reducción de las subvenciones correspondientes a las elecciones de dicho Parlamento elaboradas en 1999, partiendo de los resultados de fiscalización obtenidos por la Sindicatura de Cuentas de Cataluña.

En palabras del Presidente del Tribunal, el señor Nieto de Alba, "con carácter general, las cuentas anuales presentadas no recogen la actividad económico-financiera completa de la organización local ni la de los grupos de cargos electos de las corporaciones locales. Por otra parte, en la mayoría de las formaciones políticas con representación en el Parlamento Europeo no figura incluida la contabilidad de la representación parlamentaria. 
Según las informaciones obtenidas por el Tribunal, en 1999 la financiación pública para el funcionamiento ordinario se eleva a 21.264 millones de pesetas. Dentro de este importe se incluyen: 4.373 millones procedentes de las corporaciones locales para subvencionar a los grupos constituidos en las mismas, así como 500 millones procedentes del Gobierno Vasco para subvencionar el funcionamiento ordinario de las formaciones con representación en el Parlamento de dicha comunidad;..., estos dos recursos no están incluidos entre las fuentes de financiación pública enumeradas en el artículo 2 de la Ley Orgánica 3/1987. Por otra parte, las subvenciones electorales recibidas en 1999, correspondientes a diversos procesos electorales, ascienden a 10.732 millones de pesetas.

En relación con las operaciones de endeudamiento, se han puesto de manifiesto deficiencias en el registro contable y en el control interno similar a las de ejercicios anteriores. Destaca la existencia de operaciones que no han sido objeto de amortización en los plazos vencidos, que afectan a seis formaciones políticas con una deuda pendiente de al menos 4.301 millones de pesetas. Dos formaciones políticas han obtenido condonación parcial de sus deudas con entidades de crédito en al menos 395 millones de pesetas.

El informe reitera a este respecto que la condonación de deudas financieras es una aportación extraordinaria que no está incluida entre las fuentes de financiación previstas en la Ley orgánica 3/1987, con lo que se considera necesario disponer de una normativa expresa que contemple su autorización o prohibición, y que en todo caso establezca el régimen al que debe someterse.".

Respecto al funcionamiento interno de los partidos, ha de recordarse que entre los días 25 y 27 enero se celebró en Madrid el XIV Congreso del Partido Popular, que concluyó con la aprobación de cuatro ponencias relativas a "Los Estados en el siglo XXI", "El patriotismo constitucional en el siglo XXI"; "La sociedad del pleno empleo y de las oportunidades" y la relativa a los Estatutos. No hubo cambios significativos en el Comité de Dirección del partido y el Presidente del mismo, José María Aznar, reiteró su intención de no ser candidato a la Presidencia del Gobierno en las próximas elecciones generales.

A propósito de los procesos electorales, han de mencionarse las leyes autonómicas que introdujeron la obligatoriedad de que en las listas electorales a los Parlamentos respectivos los candidatos se coloquen de manera que no vayan seguidas dos personas del mismo sexo: ocurrió con la Ley 6/2002, de 21 de junio, de modificación de la Ley $8 / 1986$, de 26 de noviembre, electoral de la Comunidad Autónoma de las Illes Balears (BOBA n..$^{\circ}$, de 2 de julio) y con la Ley 11/2002, de 27 de junio, de modificación de la Ley 5/1986, de 23 de diciembre, electoral de Castilla-La Mancha (DOCM n. ${ }^{\circ} 79,28$ de junio); ambas modi- 
ficaciones fueron recurridas por el Presidente del Gobierno ante el Tribunal Constitucional y éste ha acordado mantener la suspensión de su aplicación hasta que se pronuncie sobre su constitucionalidad, con lo que sus previsiones no son operativas en las elecciones autonómicas de 25 de mayo de 2003.

\section{ÓRGANOS CONSTITUCIONALES Y AUTONÓMICOS}

En lo relativo a las Cortes Generales no se produjeron reformas normativas que afectaran a la organización y funcionamiento de las Cámaras, cosa que sí ocurrió en algunas Asambleas Legislativas de las Comunidades Autónomas; es el caso de la Aprobación de la reforma total del Reglamento de la Asamblea Regional de Murcia (BORM n. ${ }^{\circ}$ 155 , de 6 de julio), y de las modificaciones introducidas en las leyes electorales de las Illes Balears y de Castilla-La Mancha a las que se acaba de hacer mención.

El Senado procedió a la elección del titular de la Presidencia de la Cámara, luego de la renuncia de Esperanza Aguirre; como ya había anticipado José María Aznar en un mitin en el mes de agosto, resultó elegido Juan José Lucas con 155 votos (los de los Senadores del Grupo Popular, del Grupo Catalán de Convergència i Unió y los Senadores de Coalición Canaria); hubo 75 votos en blanco (de los Senadores Socialistas y de Entesa Catalana de Progrés) y 9 nulos (de los Senadores Nacionalistas Vasco y del Grupo Mixto). Además, la Cámara Alta nombró como Magistrado del Tribunal Constitucional a Jorge Rodríguez-Zapata Pérez (Real Decreto 1372/2002, de 18 de diciembre, BOE n. ${ }^{\circ} 303$, de 19 de diciembre), para ocupar la vacante dejada por Fernando Garrido Falla (Real Decreto 1316/2002, de 9 de diciembre, por el que se declara el cese en sus funciones, BOE n. ${ }^{\circ} 295$, de 10 de diciembre).

Por lo que respecta a la actividad legislativa de las Cortes Generales, se aprobaron a lo largo de 2002 diez Leyes Orgánicas:

la Ley Orgánica 1/2002, de 22 de marzo, reguladora del derecho de asociación (BOE $n .^{\circ} 73$, de 26 de marzo); la Ley Orgánica 2/2002, de 6 de mayo, reguladora del control judicial previo del Centro Nacional de Inteligencia (BOE $n .^{\circ} 109$, de 7 de mayo); la Ley Orgánica 3/2002, de 22 de mayo, por la que se modifican la Ley Orgánica 10/1995, de 23 de noviembre, del Código Penal, y la Ley Orgánica 13/1985, de 9 de diciembre, del Código Penal Militar, en materia de delitos relativos al servicio militar y a la prestación social sustitutoria (BOE n. ${ }^{\circ}$ 123, de 23 de mayo); la Ley Orgánica 4/2002, de 23 de 
mayo, complementaria de la Ley por la que se aprueba el concierto económico con la Comunidad Autónoma del País Vasco (BOE n. ${ }^{\circ} 124$, de 24 de mayo); la Ley Orgánica 5/2002, de 19 de junio, de las cualificaciones y de la formación profesional (BOE $n .^{\circ} 147$, de 20 de junio); la Ley Orgánica 6/2002, de 27 de junio, de Partidos Políticos (BOE n. ${ }^{\circ}$ 154, de 28 de juniol; la Ley Orgánica 7/2002, de 5 de julio, de reforma parcial de la Ley de Enjuiciamiento Criminal (BOE n. ${ }^{\circ} 161$, de 6 de julio); la Ley Orgánica 8/2002, de 24 de octubre, complementaria de la Ley de reforma parcial de la Ley de Enjuiciamiento Criminal, sobre procedimiento para el enjuiciamiento rápido e inmediato de determinados delitos $y$ faltas, y de modificación del procedimiento abreviado (BOE $n .^{\circ} 258$, de 28 de octubre); la Ley Orgánica 9/2002, de 10 de diciembre, de modificación de la Ley Orgánica 10/1995, de 23 de noviembre, del Código Penal, y del Código Civil, sobre sustracción de menores (BOE $n .^{\circ} 296$, de 11 de diciembre) y la Ley Orgánica 10/2002, de 23 de diciembre, de calidad de la educación (BOE n. ${ }^{\circ} 307$ de 24 de diciembre).

Además, se aprobaron 53 Leyes ordinarias, a las que se hará referencia en los diferentes apartados de esta Crónica.

En lo que a los Presupuestos se refiere, han de mencionarse la Ley 52/2002, de 30 diciembre, de Presupuestos generales del Estado para el año 2003 y la Ley 53/2002, de 30 diciembre, de medidas fiscales, administrativas y del orden social (ambas en el BOE n. ${ }^{\circ} 313$, de 31 de diciembre). Además han de recordarse los Recursos de Inconstitucionalidad promovidos por el Parlamento de Cataluña, el Consejo de Gobierno de la Generalidad de Cataluña, el Consejo de Gobierno del Principado de Asturias, las Cortes de Castilla-La Mancha, el Consejo de Gobierno de la Junta de Comunidades de Castilla-La Mancha, el Gobierno de Aragón, las Cortes de Aragón, el Gobierno de la Junta de Extremadura y Diputados del Grupo Parlamentario Socialista en el Congreso en relación con determinados preceptos de la Ley 18/2001, de 12 de diciembre, General de Estabilidad Presupuestaria y de la Ley Orgánica 5/2001, de 13 de diciembre, complementaria de la citada Ley.

En relación con la actividad política y de control del Congreso de los Diputados, se celebró el Debate sobre el Estado de la Nación los días 15 y 16 de julio.

A propósito de los Órganos Auxilares de las Cortes Generales, hemos de decir que el Defensor del Pueblo presentó el 20 de junio el ciol.htm.

3 Puede consultarse en la página: http://www.defensordelpueblo.es/lni- 
Informe correspondiente a la gestión realizada durante el año $2001^{3}$, en el que se explica que en dicho año se recibiron 13.186 quejas, a las que hay que sumar 179 quejas iniciadas de oficio por la propia Institución. De las quejas recibidas se inadmitieron 5.657; de las admitidas se tramitaron a lo largo del año 6.223. Además, la Institución formuló 153 recomendaciones y 178 sugerencias; de las primeras se aceptaron 76 y de las segundas 73 . Se puede leer en el Informe que, entre las administraciones notoriamente entorpecedoras por dificultar u obstaculizar la labor de la Institución, destacan el Ministerio de Fomento, en el ámbito de la Administración General del Estado; la Comunidad Foral de Navarra, en el ámbito de la Administración autonómica, y los ayuntamientos de Las Rozas, Leganés, Madrid capital y Marbella, en el de la Administración local.

En el ámbito autonómico cabe mencionar la Ley 1/2002, de 26 de marzo, por la que se modifica la Ley $6 / 1984$, de 5 de junio, del Valedor do Pobo (DOG n. ${ }^{\circ} 65$, de 4 de abril).

En materia de control de cuentas, se pueden mencionar la Ley del Parlamento Catalán 7/2002, de 25 de abril, de modificación de la Ley 6/1984, de 5 de marzo, de la Sindicatura de Cuentas, modificada por la Ley 15/1991, de 4 de julio (DOGC $n .^{\circ} 3627$, de 2 de mayo) y la Ley 2/2002, de 9 de abril, reguladora del Consejo de Cuentas de Caștilla y León (BOCL $n .^{\circ} 76$, de 22 de abril).

En el Gobierno de la Nación se produjo una importante remodelación ministerial el 9 de julio: Mariano Rajoy abandona el Ministerio del Interior y pasa a ser Vicepresidente Primero y Ministro de la Presidencia, asumiendo las funciones de Portavoz del Gobierno; Aṇa Palacio es la nueva Ministra de Asuntos Exteriores, sustituyendo a Josep Piqué, que a su vez reemplaza a Anna Birulés en el Ministerio de Ciencia y Tecnología; José María Michavila es nombrado Ministro de Justicia en sustitución de Ángel Acebes, que pasa a ser el Ministro del Interior; Eduardo Zaplana es el nuevo Ministro de Trabajo, Ana Pastor Ministra de Sanidad y Javier Arenas Ministro de Administraciones Públicas; abandonan el Gobierno el anterior Portavoz, Pío Cabanillas; Juan Carlos Aparicio (Trabajo); Juan José Lucas (Presidencia); Jesús Posada (Administraciones Públicas); Celia Villalobos (Sanidad) y la ya citada Anna Birulés. Los Decretos de Cese y Nombramiento aparecen publicados en el BOE $n .^{\circ} 164$, de 10 de julio.

Tambien se produjo un significativo cambio gubernamental en el Gobierno de Cataluña el 4 de noviembre, con la sustitución de cuatro Consejeros, la reducción de 15 a 13 del número de Consejerías y numerosas remodelaciones en las competencias de cada una de ellas. 
Por lo que a la actividad legislativa del Gobierno se refiere, cabe destacar el Real Decreto Legislativo 1/2002, de 29 de noviembre, por el que se aprueba el texto refundido de la Ley de Regulación de los Planes y Fondos de Pensiones (BOE n. 298 , de 13 de diciembre); el Real Decreto-ley 3/2002, de 10 de mayo, por el que se autoriza la incorporación y afectación de remanentes de crédito para atender al pago de indemnizaciones derivadas de la aplicación de la Ley 32/1999, de 8 de octubre, de solidaridad con las víctimas del terrorismo (BOE $n .^{\circ} 113$, de 11 de mayo); el Real Decreto-ley 5/2002, de 24 de mayo, de medidas urgentes para la reforma del sistema de protección por desempleo y mejora ocupacional (BOE $n .^{\circ} 125$, de 25 de mayo) y el Real DecretoLey $7 / 2002$, de 22 de noviembre, sobre medidas reparadoras en relación con el accidente del buque "Prestige" (BOE n. 281 , de 23 de noviembre). De esta misma fecha y BOE es el Real Decreto 1220/2002, por el que se crea la Comisión Interministerial para el seguimiento de los daños ocasionados por el buque "Prestige».

Además, se aprobaron el Real Decreto-Ley 8/2002, de 13 de diciembre, por el que se amplían las medidas reparadoras en relación con el accidente del buque "Prestige" a las Comunidades Autónomas del Principado de Asturias, Cantabria y País Vasco y se modifica el Real Decreto-ley $7 / 2002$, de 22 de noviembre (BOE n. ${ }^{\circ} 299$, de 14 de diciembre); el Real Decreto-Ley 9/2002, de 13 de diciembre, por el que se adoptan medidas para buques tanque que transporten mercancias peligrosas o contaminantes (BOE $n .^{\circ} 299$, de 14 de diciembre) y el Real Decreto-Ley 10/2002, de 27 de diciembre, por el que se amplían los compromisos de los militares profesionales que mantienen una relación de servicio de carácter temporal con las Fuerzas Armadas. (BOE n. ${ }^{\circ} 313$, de 31 de diciembre).

Contra algunos preceptos del Real Decreto-ley 5/2002, de 24 de mayo, de medidas urgentes para la reforma del sistema de protección por desempleo y mejora ocupacional se presentó una Cuestión de Inconstitucionalidad por el Juzgado de lo Social $n .^{\circ} 2$ de Badajoz, y diversos Recursos de Inconstitucionalidad suscritos por los Gobiernos de Extremadura, Andalucía, Baleares y Asturias, así como por Diputados del Congreso de los Grupos Socialista, Izquierda Unida y Mixto.

En lo que se respecta al Poder Judicial, han de mencionarse los siguientes Acuerdos Reglamentarios: el 1/2002, de 8 de mayo, del Pleno del Consejo General del Poder Judicial, por el que se modifica el Reglamento 2/1995, de 7 de junio, de la Escuela Judicial (BOE n. ${ }^{\circ} 118$, de 17 de mayo); el 2/2002, de 8 de mayo, del Pleno del Consejo del Poder Judicial, por el que se aprueba la modificación del Reglamento 
5/1995, de 7 de junio, de los aspectos accesorios de las actuaciones judiciales (BOE n. ${ }^{\circ} 118$, de 17 de mayo) y el 3/2002, de 19 de junio, del Pleno del Consejo General del Poder Judicial, por el que se modifica el Reglamento 1/1995, de 7 de junio, de la Carrera Judicial, en lo relativo a permisos y licencias (BOE $n .{ }^{\circ} 155$, de 29 de junio).

En la Sentencia de 14 de junio de 2002, la Sala 2. ${ }^{\text {a }}$ del Tribunal Supremo confirmó la doctrina sobre la competencia internacional de los tribunales españoles en relación con los delitos de terrorismo y de exaltación de la actividad terrorista.

Por lo que al Tribunal Constitucional se refiere, como ya se ha dicho, el Senado nombró como Magistrado a Jorge Rodríguez-Zapata Pérez (Real Decreto 1372/2002, de 18 de diciembre, BOE n. ${ }^{\circ} 303$, de 19 de diciembre), para ocupar la vacante dejada por Fernando Garrido Falla (Real Decreto 1316/2002, de 9 de diciembre, por el que se declara el cese en sus funciones, BOE $n .^{\circ} 295$, de 10 de diciembre).

Además, el Pleno del Alto Tribunal adoptó los siguientes Acuerdos: Acuerdo de 19 de diciembre de 2002 por el que se regula el régimen de retribuciones del personal al servicio del Tribunal Constitucional (BOE $n .{ }^{\circ}$ 307, de 24 de diciembre) y Acuerdo de 19 de diciembre por el que se modifica parcialmente el reglamento de organización y personal del Tribunal Constitucional y se aprueba una nueva relación de puestos de trabajo del personal a su servicio (BOE $n .^{\circ} 307$, de 24 de diciembre).

No debe dejar de citarse la Sentencia de 21 de enero de 2002, de la Sala 3. del Tribunal Supremo, por la que se decide la desestimación del recurso interpuesto contra la inactividad del Tribunal Constitucional por no convocar concurso-oposición para cubrir plazas de letrado.

Por lo que se refiere a la tarea jurisdiccional del Tribunal como "legislador negativo" han de mencionarse las siguientes sentencias:

En la STC 10/2002, el Tribunal resolvió la Cuestión de Inconstitucionalidad planteada por la Audiencia Provincial de Sevilla respecto del art. 557 de la Ley de Enjuiciamiento Criminal. A juicio del Tribunal dicho precepto es contrario al art. 18.2 de la Constitución por cuanto excluye expresamente la posibilidad de que las habitaciones de los huéspedes de los hoteles puedan considerarse su domicilio a los efectos de que la entrada y registro en las mismas requieran autorización judicial. Por ello, se estimó la cuestión y, en su virtud, se declaró inconstitucional y derogado el art. 557 de la Ley de Enjuiciamiento Criminal. 
En la STC 53/2002, el Pleno desestimó el recurso interpuesto contra el art. 5.7 de la Ley de Asilo que prevé la retención en frontera de los peticionarios de asilo que no reúnan las condiciones legales para entrar en España en tanto se resuelva sobre la admisibilidad de su petición. A juicio del Tribunal, esa retención no constituye una detención gubernativa ni es una limitación directa de la libertad personal de peticionario, sino la regulación del tiempo, modo y lugar de la momentánea restricción de su libertad deambulatoria en la frontera si desea esperar en ella a la notificación del resultado de su petición. En la medida en que esa retención, no coactiva, es proporcionada, no infringe el art. 17 de la Constitución. Además, luego del análisis del régimen jurídico del derecho de asilo, se concluye que no se trata de un derecho fundamental.

La STC 97/2002 resolvió el recurso de inconstitucionalidad formulado contra una Ley a la que se reprocha que la Mesa del Congreso la sometió a votación directa por el Pleno haciendo caso omiso del "veto implícito" que le había formulado el Senado. Para el Tribunal no hay más veto que el que expresa y formalmente se formula como tal, y no cabe equiparar al mismo una enmienda a la totalidad aprobada por el Senado o, como fue el caso, si el texto es rechazado - sin máspor esa Cámara. Si no hay "veto expreso" el trámite debe ser el ordinario, esto es, la Mesa del Congreso da curso al texto remitido originariamente al Senado para que se vote por el Pleno.

En la STC 113/2002 se desestimó la Cuestión de Inconstitucionalidad planteada contra la Ley de Seguridad Vial en lo relativo a la potestad de la Administración para imponer en el caso de infracciones graves la retirada del permiso de conducir como sanción suplementaria. El Juez a quo cuestionaba la habilitación en blanco que tal norma contenía, ya que dejaba en manos de la Administración decidir si imponía o no esa sanción suplementaria. El Tribunal afirma que en este caso el principio de predeterminación de la conducta y la sanción, y el principio de correspondencia entre una y otra, no están sujetas a la reserva de ley absoluta, propio del ámbito penal. Por otro lado, señala que debe reconocérsele a la Administración un margen de libertad para graduar las sanciones concretas. La propia Ley de Seguridad Vial fija unos criterios a los que la Administración debe atender al decidir si impone aquella sanción de retirada de permiso, lo que para el Tribunal aleja toda duda sobre una intolerable habilitación en blanco lesiva del art. 25 de la Constitución.

A través de la STC 202/2002 el Tribunal se autocuestionó la constitucionalidad de los arts. 453 y 468 Ley Orgánica Procesal Militar en 
lo relativo a la irrecurribilidad judicial de las sanciones disciplinarias leves. También se afirma que la disciplina militar puede justificar límites específicos a los derechos fundamentales, pero en ningún caso es un terreno inmune a su eficacia.

La STC 204/2002 resolvió el Recurso de Inconstitucionalidad planteado por el Consejo Ejecutivo de la Generalidad de Cataluña contra los arts. 24 y 166 de la Ley 13/1996, de 30 de diciembre, de medidas fiscales, administrativas y del orden social, y lo estimó parcialmente, declarando que a) Que es inconstitucional y nulo el inciso "en todo el territorio nacional», del título del art. 24 de la Ley y de su apartado uno; b) Que es inconstitucional y nulo el apartado tres del art. 24 de la Ley; c) Que el art. 166.1 de la Ley no vulnera el orden constitucional de competencias interpretado en el sentido señalado en el fundamento jurídico 8, párrafo penúltimo; d) Que el art. 166.2, párrafo segundo, inciso referente a la formulación del plan especial por Aeropuertos Españoles y Navegación Aérea, no vulnera el orden constitucional de competencias, interpretado en el sentido señalado en el fundamento jurídico 11, párrafo penúltimo y e) Que es inconstitucional y nulo el art. 166.3 de la Ley.

\section{ORGANIZACIÓN TERRITORIAL DEL ESTADO}

Por lo que se refiere al "Estado autonómico", cabe mencionar las siguientes Leyes aprobadas por las Cortes Generales: la Ley Orgánica 4/2002, de 23 de mayo, complementaria de la Ley por la que se aprueba el concierto económico con la Comunidad Autónoma del País Vasco; la Ley 12/2002, de 23 de mayo, por la que se aprueba el concierto económico con la Comunidad Autónoma del País Vasco y la Ley 13/2002, de 23 de mayo, por la que se aprueba la metodología de señalamiento del cupo del País Vasco para el quinquenio 2002-2006 (las tres en el BOE $n .^{\circ} 124$, de 24 de mayo de 2002).

Por otra parte, se aprobaron las siguientes normas: la Ley 17/2002, de 1 de julio, del régimen de cesión de tributos del Estado a la Generalidad de Cataluña y de fijación del alcance y condiciones de dicha cesión; y con la misma denominación y contenido la Ley 18/2002 para Galicia; la Ley 19/2002 para Andalucía; la Ley 20/2002 para el Principado de Asturias; la Ley 21/2002 para Cantabria; la Ley 22/2002 para La Rioja; la Ley 23/2002 para la Región de Murcia; la Ley 24/2002 para la Comunidad Valenciana; la Ley 25/2002 para Aragón; la Ley 26/2002 para Castilla-La Mancha; la Ley 27/2002 para Canarias; la Ley 28/2002 
para Extremadura; la Ley 29/2002 para las Illes Balears; la Ley 30/2002 para la Comunidad Autónoma de Madrid, y la Ley 31/2002 para Castilla y León (todas en el BOE n. ${ }^{\circ} 157$, de 2 de julio de 2002).

En el ámbito jurisprudencial, hemos de referirnos a la STC 96/2002, que resuelve el caso de las "vacaciones fiscales" vascas y navarras. El Tribunal recuerda su doctrina sobre el sentido del «ámbito propio de competencias" a los efectos del recurso de inconstitucionalidad interpuesto por Comunidades Autónomas (la recurrente en este caso fue La Riojal, definiéndolo como el derivado de las facultades correspondientes a los intereses peculiares de cada Comunidad. El Tribunal aprecia una inconstitucionalidad por omisión relativa en la norma que excluye tácitamente (al incluir sólo a otros) de dichas "vacaciones" a cierto género de posibles beneficiarios.

En la STC 126/2002 se resuelve un conflicto positivo de competencias relativo a subvenciones en materia de medio ambiente en la que lo interesante no es tanto la doctrina sobre las subvenciones, que en términos generales se reitera (el Estado puede acordar en uso del poder de gasto qué subvencionar, aunque no sea materia estatal, pero el desarrollo, gestión y ejecución de la subvención siempre corresponde a las Comunidades Autónomas en las materias de su competencia). La cuestión está en el anudamiento de la subvención a la competencia básica del Estado sobre medio ambiente: para el Tribunal las subvenciones en medio ambiente tienen la misma condición de «básicas" que aquello que subvencionan. Debe mencionarse también que en esta Sentencia se establecen criterios para determinar si ha habido o no pérdida sobrevenida del objeto en los conflictos, y se concluye que la controversia competencial perdura si no ha habido desistimientos, si la nueva norma plantea idénticos problemas competenciales y el agotamiento de los efectos económicos de la norma o medida controvertida no implica el fin de la controversia.

\section{DERECHOS, DEBERES Y LIBERTADES}

En esta cuestión se podrían clasificar los hechos más relevantes atendiendo a su impronta normativa y a su carácer jurisprudencial. En el primer ámbito habría que referirse, a grandes rasgos, a las numerosas normas aprobadas a lo largo del año 2002, tanto en el ámbito estatal como autonómico.

En primer lugar, y por seguir la ubicación de las materias en el articulado de la Constitución, ha de mencionarse, la Ley $36 / 2002$, de 8 
de octubre, de modificación del Código Civil en materia de nacionalidad (BOE . $^{\circ} 242$, de 9 de octubre).

En materia de extranjería e inmigración, se aprobó la Ley 32/2002, de 5 de julio, de modificación de la Ley 17/1999, de 18 de mayo, de régimen del personal de las Fuerzas Armadas, al objeto de permitir el acceso de extranjeros a la condición de militar profesional de tropa y marinería (BOE $n .^{\circ} 161$, de 6 de julio).

Para promover la igualdad, se aprobaron la Ley Foral 33/2002, de 28 de noviembre, de fomento de la igualdad de oportunidades entre mujeres y hombres (BON $n .^{\circ} 150$, de 13 de diciembre) y las leyes 22/2002, de 21 de noviembre, de creación del Instituto de la Mujer de Castilla-La Mancha (DOCM de 4 de diciembre) y 12/2002, de 3 de diciembre, de creación del Instituto de la Mujer de la Región de Murcia (BORM de 24 de diciembre).

Respecto a la protección de la vida y la integridad física cabe citar la Ley Foral 22/2002, de 2 de julio, para la adopción de medidas integrales contra la violencia sexista (BON $n .^{\circ} 84$, de 12 de julio).

Sobre libertad personal y seguridad, han de mencionarse la Ley Orgánica 2/2002, de 6 de mayo, reguladora del control judicial previo del Centro Nacional de Inteligencia (BOE $n .^{\circ} 109$, de 7 de mayo) y la Ley $11 / 2002$, de 6 de mayo, reguladora del Centro Nacional de Inteligencia (BOE n. ${ }^{\circ}$ 109, de 7 de mayo); la Ley Orgánica 3/2002, de 22 de mayo, por la que se modifican la Ley Orgánica 10/1995, de 23 de noviembre, del Código Penal, y la Ley Orgánica 13/1985, de 9 de diciembre, del Código Penal Militar, en materia de delitos relativos al servicio militar y a la prestación social sustitutoria (BOE $n .^{\circ} 123$, de 23 de mayo); la Ley Orgánica 7/2002, de 5 de julio, de reforma parcial de la Ley de Enjuiciamiento Criminal (BOE n. ${ }^{\circ} 161$, de 6 de julio); la Ley Orgánica $8 / 2002$, de 24 de octubre, complementaria de la Ley de reforma parcial de la Ley de Enjuiciamiento Criminal, sobre procedimiento para el enjuiciamiento rápido e inmediato de determinados delitos $y$ faltas, $y$ de modificación del procedimiento abreviado (BOE $n .^{\circ} 258$, de 28 de octubre); la Ley Orgánica 9/2002, de 10 de diciembre, de modificación de la Ley Orgánica 10/1995, de 23 de noviembre, del Código Penal, y del Código Civil, sobre sustracción de menores (BOE n. ${ }^{\circ} 296$, de 11 de diciembre) y la Ley 38/2002, de 24 de octubre, de reforma parcial de la Ley de Enjuiciamiento Criminal, sobre procedimiento para el enjuiciamiento rápido e inmediato de determinados delitos y faltas, y de modificación del procedimiento abreviado (BOE n. ${ }^{\circ} 258$, de 28 de octubre). 
Respecto a la protección de datos, se aprobó la Ley 5/2002, de 19 de abril, de la Agencia Catalana de Protección de Datos (DOGC n. ${ }^{\circ}$ 3625 , de 29 de abril).

Sobre libertad de información, se pueden citar el Protocolo de enmienda al Convenio europeo sobre la Televisión Transfronteriza hecho en Estrasburgo el 9 de septiembre de 1998 (BOE n. ${ }^{\circ}$ 92, de 17 de abril); la Ley 34/2002, de 11 de julio, de Servicios de la sociedad de la información y de comercio electrónico (BOE n. ${ }^{\circ} 166$, de 12 de julio); la Ley 4/2002, de 4 de abril, de modificación de la Ley 3/2000, de 26 de mayo, de creación del Ente Público de Radio-Televisión de Castilla-La Mancha (DOCM n. ${ }^{\circ} 46$, de 15 de abril) y la Ley Foral 17/2002, de 6 de junio, de modificación de la Ley Foral 18/2001, de 5 de julio, por la que se regula la actividad audiovisual en Navarra y se crea el Consejo Audiovisual de Navarra (BON n. ${ }^{\circ} 72$, de 14 de junio).

En lo que respecta al derecho de asociación, se aprobaron la Ley Orgánica 1/2002, de 22 de marzo, reguladora del derecho de asociación (BOE n. ${ }^{\circ} 73$, de 26 de marzo) y la Ley Orgánica 6/2002, de 27 de junio, de Partidos Políticos (BOE n. ${ }^{\circ}$ 154, de 28 de junio).

Sobre el derecho de acceso a los cargos públicos representativos, hemos de recordar otra vez los cambios introducidos por la Ley 6/2002, de 21 de junio, de modificación de la Ley 8/1986, de 26 de noviembre, electoral de la Comunidad Autónoma de las Illes Balears (BOBA n..$^{\circ}$, de 2 de julio) y la Ley 11/2002, de 27 de junio, de modificación de la Ley $5 / 1986$, de 23 de diciembre, electoral de Castilla-La Mancha (DOCM n. ${ }^{\circ} 79,28$ de junio).

En materia de tutela judicial, han de citarse el Real Decreto-ley $3 / 2002$, de 10 de mayo, por el que se autoriza la incorporación y afectación de remanentes de crédito para atender al pago de indemnizaciones derivadas de la aplicación de la Ley 32/1999, de 8 de octubre, de solidaridad con las víctimas del terrorismo (BOE $n .^{\circ} 113$, de 11 de mayo) y la Ley $37 / 2002$, de 8 de octubre, sobre concesión de un crédito extraordinario, por importe de $4.648 .044,15$ euros, para el pago de indemnizaciones derivadas del cumplimiento de distintos autos dictados en ejecución de la sentencia del Tribunal Supremo, Sala de lo Contencioso-Administrativo, Sección Sexta, de 20 de octubre de 1997, en los que se reconoce el derecho de los reclamantes a ser indemnizados por los daños ocasionados por la rotura de la presa de Tous (BOE $n .^{\circ}$ 242, de 9 de octubre).

Sobre el derecho a la educación, han de citarse la Ley Orgánica 10/2002, de 23 de diciembre, de calidad de la educación (BOE n. 307 
de 24 de diciembre); la Ley Orgánica 5/2002, de 19 de junio, de las cualificaciones y de la formación profesional (BOE $n .^{\circ} 147$, de 20 de junio); la Ley 5/2002, de 19 de junio, de creación del Consejo Valenciano de Universidades y de la Comisión Valenciana de Acreditación y Evaluación de la Calidad en el Sistema Universitario Valenciano (DOGV n. ${ }^{\circ}$ 4279, de 22 de junio); la Ley Foral 26/2002, de 2 de julio, de medidas para la mejora de las enseñanzas no universitarias (BON n. ${ }^{\circ} 84$, de 20 de agosto) y la Ley 12/2002, de 18 de diciembre, de Consejos Sociales de las Universidades Públicas de la Comunidad de Madrid (BOCM n. ${ }^{\circ}$ 304 , de 23 de diciembre).

En otros ámbitos, la Ley $16 / 2002$, de 28 de junio, de educación permanente de Aragón (BOA n..$^{\circ} 79$, de 8 de julio); la Ley Foral 19/2002, de 21 de junio, reguladora de la educación de personas adultas (BON n. ${ }^{\circ} 199$, de 20 de agosto) y la Ley 23/2002, de 21 de noviembre, de Educación de Personas Adultas de Castilla-La Mancha (DOCM de 4 de diciembre).

Sobre libertad sindical, la Ley 26/2002, de 28 de noviembre, de modificación de la Ley 10/1994, de 11 de julio, de la policía de la Generalidad-mozos de escuadra, en relación con la afiliación sindical de los miembros del cuerpo de mozos de escuadra (DOGC $n .^{\circ} 3776$, de 5 de diciembre).

En materia de defensa, debe citarse la Ley 32/2002, de 5 de julio, de modificación de la Ley 17/1999, de 18 de mayo, de régimen del personal de las Fuerzas Armadas, al objeto de permitir el acceso de extranjeros a la condición de militar profesional de tropa y marinería (BOE n. ${ }^{\circ} 161$, de 6 de julio).

En cuestiones tributarias han de citarse el Real Decreto 594/2002, de 28 de junio, por el que se modifica el Reglamento del Impuesto sobre la Renta de las Personas Físicas, aprobado por el Real Decreto 214/1999, de 5 de febrero, en materia de exenciones, rendimientos del trabajo y del capital mobiliario, deducciones, autoliquidación y retenciones (BOE n. ${ }^{\circ} 167$, de 13 de julio); la Ley 46/2002, de 18 de diciembre, de reforma parcial del Impuesto sobre la Renta de las Personas Físicas y por la que se modifican las Leyes de los Impuestos sobre Sociedades y sobre la Renta de no Residentes (BOE n. ${ }^{\circ} 303$, de 19 de diciembre); la Ley 49/2002, de 23 de diciembre, de régimen fiscal de las entidades sin fines lucrativos y de los incentivos fiscales al mecenazgo (BOE n. 307 de 24 de diciembre) y la Ley 51/2002, de 27 de diciembre, de reforma de la Ley 39/1988, de 28 de diciembre, reguladora de las haciendas locales (BOE n. ${ }^{\circ} 311$, de 28 de diciembre). 
En el ámbito autonómico, la Ley $8 / 2002$, de 14 de noviembre, de Reforma Fiscal de la Comunidad Autónoma de Extremadura (DOE de 14 de diciembre); la Ley $21 / 2002$, de 14 de noviembre, de medidas fiscales de apoyo a la familia y a determinados sectores económicos y de gestión tributaria de Castilla-La Mancha (DOCM n ${ }^{\circ}{ }^{146}$, de 25 de noviembre); el Decreto Legislativo 1/2002, de 19 de noviembre, por el que se aprueba el Texto Refundido de la Ley de Hacienda de CastillaLa Mancha (DOCM de 29 de noviembre) y la Ley 10/2002, de 21 de noviembre, por la que se regula el tramo autonómico del Impuesto sobre la Renta de las Personas Físicas en la Comunidad Autónoma de Canarias (BOCA n. ${ }^{\circ} 157$, de 27 de noviembre).

En cuanto al derecho de propiedad, ha de citarse la Ley 48/2002, de 23 de diciembre, del Catastro Inmobiliario (BOE de 24 de diciembre).

Sobre el derecho de fundación, se aprobaron la Ley 50/2002, de 26 de diciembre, de Fundaciones (BOE n. ${ }^{\circ} 310$ de 27 de diciembre) y la Ley 13/2002, de 15 de julio, de fundaciones de Castilla y León (BOCL n. ${ }^{\circ} 139$, de 19 de julio).

En materia de empleo y trabajo, deben mencionarse el Real Decreto-ley 5/2002, de 24 de mayo, de medidas urgentes para la reforma del sistema de protección por desempleo y mejora ocupacional (BOE n. ${ }^{\circ} 125$, de 25 de mayo); la Ley 45/2002, de 12 de diciembre, de medidas urgentes para la reforma del sistema de protección por desempleo y mejora de la ocupabilidad (BOE n. 298 de 13 de diciembre) y el Real Decreto 1426/2002, de 27 de diciembre, por el que se fija el salario mínimo interprofesional para 2003 en 451,20 euros al mes (BOE n. ${ }^{\circ} 311$, de 28 de diciembre); además de la Ley 33/2002, de 5 de julio, de modificación del artículo 28 del Texto Refundido de la Ley del Estatuto de los Trabajadores, aprobado por el Real Decreto Legislativo $1 / 1995$, de 24 de marzo (BOE n. ${ }^{\circ} 161$, de 6 de julio).

En el ámbito autonómico, la Ley Foral 16/2002, de 31 de mayo, por la que se regulan aspectos de acceso al empleo de las personas con discapacidad en la Comunidad Foral de Navarra (BON n. ${ }^{\circ} 69$, de 7 de junio) y la Ley 17/2002, de 4 de julio, de ordenación del sistema de empleo y la creación del Servicio de Empleo de Cataluña (DOGC n. ${ }^{\circ}$ 3476, de 12 de julio).

Sobre el ejercicio de profesiones tituladas, ha de citarse el Real Decreto 1281/2002, de 5 de diciembre, por el que se aprueba el Estatuto General de los Procuradores de los Tribunales de España (BOE n. ${ }^{\circ}$ 305 de 21 de diciembre de 2002). 
Respecto a la protección de la familia y los menores, debe recordarse la Ley Orgánica 9/2002, de 10 de diciembre, de modificación de la Ley Orgánica 10/1995, de 23 de noviembre, del Código Penal, y del Código Civil, sobre sustracción de menores (BOE n. ${ }^{\circ} 296$, de 11 de diciembre).

En el ámbito autonómico, la Ley 6/2002, de 25 de a bril, de medidas relativas a la conciliación del trabajo con la vida familiar del personal de las administraciones públicas catalanas y de modificación de los artículos 96 y 97 del Decreto Legislativo 1/1997 (DOGC n. ${ }^{\circ} 3626$, de 30 de abril); también en Cataluña la Ley 8/2002, de 27 de mayo, de modificación de la Ley 37/1991, de 30 de diciembre, sobre medidas de protección de los menores desamparados y de la adopción, y de regulación de la atención especial a los adolescentes con conductas de alto riesgo social (DOGC $n .{ }^{\circ} 3648$, de 3 de junio); en Asturias, la Ley $4 / 2002$, de 23 de mayo, de parejas estables (BOPA n. ${ }^{\circ} 125$, de 31 de mayo). Además, la Ley 14/2002, de 25 de julio, de promoción, atención y protección a la infancia en Castilla y León (BOCL $n .^{\circ} 145$, de 29 de julio) y la Ley Foral 34/2002, de 10 de diciembre, de acogimiento familiar de personas mayores (BON n. ${ }^{\circ} 150$, de 13 de diciembre).

En materia de Seguridad Social y jubilación, la Ley 35/2002, de 12 de julio, de medidas para el establecimiento de un sistema de jubilación gradual y flexible (BOE n. ${ }^{\circ} 167$, de 13 de julio) y el Real Decreto Legislativo $1 / 2002$, de 29 de noviembre, por el que se aprueba el texto refundido de la Ley de Regulación de los Planes y Fondos de Pensiones (BOE n. ${ }^{\circ}$ 298, de 13 de diciembre).

Para la protección de los emigrantes españoles, Ley 25/2002, de 25 de noviembre, de medidas de apoyo al regreso de los catalanes emigrados y sus descendientes, y de segunda modificación de la Ley 18/1996 (DOGC $n .^{\circ} 3776$, de 5 de diciembre).

Respecto a la protección de la salud, en Navarra se aprobaron la Ley Foral 5/2002, de 21 de marzo, de modificación de la Ley Foral $10 / 1990$, de 23 de noviembre, de salud (BON n..$^{\circ} 42$, de 5 de abril) y la Ley Foral 11/2002, de 6 de mayo, sobre los derechos del paciente a las voluntades anticipadas, a la información y a la documentación clínica (BON n. ${ }^{\circ}$ 58, de 13 de mayo); en Aragón, la Ley 6/2002, de 15 de abril, de salud (BOA n. ${ }^{\circ} 46$, de 19 de abril); en La Rioja, la Ley 2/2002, de 17 de abril, de Salud (BOR n..$^{\circ} 49$, de 23 de abril); en Cataluña la Ley 20/2002, de 5 de julio, de seguridad alimentaria (DOGC $n .^{\circ} 3679$, de 7 de julio); en Castilla-La Mancha, la Ley 15/2002, de 11 de julio, sobre drogodependencias y otros trastornos adictivos (DOCM n. ${ }^{\circ} 90$, de 24 de julio) y Ley 24/2002, de 5 de diciembre, de Garantías en la 
Atención Sanitaria Especializada (DOCM de 18 de diciembre); en la Comunidad Valenciana la Ley 4/2002, de 18 de junio, por la que se modifica la Ley $3 / 1997$, de 16 de junio, sobre drogodependencias $y$ otros trastornos adictivos (DOGV $n .^{\circ} 4274$, de 19 de junio) y en Cantabria la Ley $7 / 2002$, de 10 de diciembre, de Ordenación Sanitaria (BOCA de 18 de diciembre).

Sobre el acceso a la cultura, en Baleares se aprobó la Ley 1/2002, de 19 de marzo, de cultura popular y tradicional (BOBA n. ${ }^{\circ} 38$, de 28 de marzol y en la Comunidad Valenciana la Ley $3 / 2002$, de 13 de junio, del libro (DOGV n. ${ }^{\circ} 4274$, de 19 de junio).

En materia medioambiental, deben citarse la Ley 16/2002, de 1 de julio, de prevención y control integrados de la contaminación (BOE n. ${ }^{\circ} 157$, de 2 de julio) y en el ámbito autonómico, en Asturias la Ley $6 / 2002$, de 18 de junio sobre protección de los ecosistemas acuáticos y de regulación de la pesca en aguas continentales (BOPA n. ${ }^{\circ} 151$, de 1 de julio); en Madrid la Ley 2/2002, de 19 de junio, de evaluación ambiental (BOCM n. ${ }^{\circ} 154$, de 1 de julio); en Castilla-La Mancha la Ley 12/2002, de 27 de junio, reguladora del ciclo integral del agua de la Comunidad Autónoma de Castilla-La Mancha (DOCM n. ${ }^{\circ} 83$, de 8 de julio); en Cataluña la Ley 16/2002, de 28 de junio, de protección contra la contaminación acústica (DOGC $n .^{\circ} 3675$, de 11 de julio); en La Rioja la Ley $5 / 2002$, de 8 de octubre, de protección del medio ambiente en La Rioja (BOR n..$^{\circ} 124$, de 12 de octubre) y en la Comunidad Valenciana la Ley $7 / 2002$, de 3 de diciembre, de la Generalitat Valenciana, de Protección contra la Contaminación Acústica (DOGV n. ${ }^{\circ}$ 4394, de 9 de diciembre).

En lo que respecta a la protección del patrimonio, se aprobaron la Ley 12/2002, de 11 de julio, de patrimonio cultural de Castilla y León (BOCL n. ${ }^{\circ} 139$, de 19 de julio) y la Ley 11/2002, de 21 de noviembre, por la que se modifica la Ley $4 / 1999$, de 15 de marzo, de patrimonio histórico de Canarias (BOCA n. ${ }^{\circ} 157$, de 27 de noviembre).

Sobre la protección de la juventud, cabe citar la Ley 11/2002, de 10 de julio, de Juventud de Castilla y León (BOCL $\mathrm{n}$. $^{\circ} 139$, de 19 de julio); la Ley 8/2002, de 27 de noviembre, de Juventud de la Comunidad de Madrid (BOCM n. ${ }^{\circ} 289$, de 5 de d iciembre) y la Ley $13 / 2002$, de 4 de diciembre, de creación del Instituto de la Juventud de la Región de Murcia (BORM de 24 de diciembre).

Para la protección de los consumidores y usuarios se aprobaron la Ley 39/2002, de 28 de octubre, de transposición al ordenamiento jurídico español de diversas directivas comunitarias en materia de pro- 
tección de los intereses de los consumidores y usuarios (BOE n. ${ }^{\circ} 259$, de 29 de octubre) y en Asturias la Ley 11/2002, de 2 de diciembre, de los Consumidores y Usuarios (BOPA $n .^{\circ} 287$, de 13 de diciembre).

En el ámbito jurisprudencial destacan los siguientes pronunciamientos del Tribunal Constitucional y del Tribunal Supremo:

En lo que a la igualdad se refiere, en la Sentencia de 13 de sep-

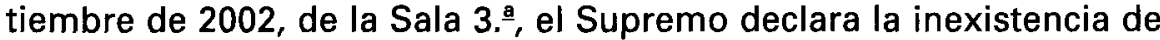
justificación razonable que ampare un trato desigual de las mujeres en la celebración de un alarde.

Respecto a la libertad religiosa, en la STC 154/2002 se resuelve el recurso de amparo interpuesto por los padres de un menor, Testigo de Jehová, que murió tras negarse a recibir una transfusión de sangre. Se había acreditado en el juicio de instancia que los padres, aunque expresaron su oposición, no habían impedido la práctica de las transfusiones necesarias, sino que fue el menor quien de forma repetida, reiterada e, incluso, violenta se negó a ello. El Tribunal estimó el amparo al considerar que a los padres no les era exigible otra conducta distinta a la seguida, ya que no se alcanza a ver cómo hubieran podido imponerse a la voluntad del menor sin exigirles por ello un desproporcionado sacrificio de su libertad religiosa (o de la integridad física del propio menor). Además, el Tribunal afirma que no existe un derecho a la propia muerte y que en el orden público del art. 16 se integran la salud pública, la seguridad pública y la moral pública.

En materia de libertad personal, en la STC 188/2002 se vuelve sobre el test de alcoholemia y se afirma que para condenar por el delito de conducción de vehículos a motor bajo los efectos del alcohol $u$ otra sustancia, no basta con la medición del alcohol en sangre, lo que constituye una infracción administrativa. Las mediciones son pericias técnicas documentadas en el atestado que requieren ser ratificadas en el juicio oral, no bastando su lectura si se cuestiona su fiabilidad, sus resultados y la relación de éstos con la conducción, o no se le ofreció al imputado una segunda prueba y la de contraste (análisis de sangre). Por otro lado, el Tribunal considera irrelevante constitucionalmente la falta de homologación del medidor. Lo relevante a los efectos del art. 24 son las condiciones en las que se practicó la prueba, con el propósito de garantizar la contradicción y evitar la indefensión, lo que se logra con el ofrecimiento del segundo examen y la prueba de alcohol en sangre, siempre que la prueba sea ratificada por los agentes que confeccionaron el atestado e incluso por otros testigos o por el propio imputado. 
A propósito del derecho al honor, en la STC 148/2002 se desestimó el recurso de amparo interpuesto por un agente de la policía local contra la sentencia de segunda instancia que absolvió de un delito de injurias al Alcalde que lo criticó en una rueda de prensa. El Tribunal sostiene que el amparo no es una vía adecuada para instar la condena penal, lo que no significa que el Alto Tribunal no pueda en ningún caso pronunciarse sobre sentencias penales absolutorias, cosa que sí puede ocurrir cuando al proceso penal se ha accedido para proteger un derecho fundamental, porque el objeto propio del amparo es la revisión de decisiones judiciales relativas a derechos fundamentales. Otra cosa es que en esos casos únicamente quepa un fallo declarativo, que no es estéril pues, además de la reparación moral, la sentencia de amparo puede ser base para la reclamación de una indemnización.

En lo que respecta al derecho a la intimidad, la STC 185/2002 lo declara vulnerado con ocasión de una crónica judicial en la que se revelan datos de la víctima de una violación que permitían su identificación y resultaban innecesarios para la información que se deseaba transmitir. El Tribunal añade que los asuntos penales, incluidas las investigaciones judiciales y policiales, poseen relevancia pública, ya que conviene que la comunidad sea informada de estas cuestiones.

Sobre el derecho a la inviolabilidad del domicilio, en la STC 10/2002, el Tribunal resolvió la Cuestión de Inconstitucionalidad planteada por la Audiencia Provincial de Sevilla respecto del art. 557 de la Ley de Enjuiciamiento Criminal. A juicio del Tribunal dicho precepto es contrario al art. 18.2 de la Constitución por cuanto excluye expresamente la posibilidad de que las habitaciones de los huéspedes de los hoteles puedan considerarse su domicilio a los efectos de que la entrada y registro en las mismas requieran autorización judicial. Por ello, se estimó la cuestión y, en su virtud, se declaró inconstitucional y derogado el art. 557 de la Ley de Enjuiciamiento Criminal.

En la STC 123/2002 se abordan la inviolabilidad del domicilio $y$ el secreto de las comunicaciones, aunque desde perspectivas novedosas. Respecto del primer derecho, el recurrente sostuvo que un delito de estafa no tenía la gravedad requerida para justificar la autorización judicial para la entrada y registro de su domicilio. Para el Tribunal es un fin constitucionalmente legítimo la persecución de los delitos graves, gravedad que no sólo debe medirse por las penas que merezcan los hechos delictivos y que le compete ponderar al Juez ordinario, quien deberá realizar un juicio de proporcionalidad entre el bien sacrificado y el fin perseguido. Al Tribunal le compete comprobar si el Juez efectuó ese juicio de proporcionalidad, y no si es o no correcto o 
adecuado. Respecto del secreto de las comunicaciones, la cuestión se planteó respecto de la adecuación constitucional de la Providencia del Juez, dictada a instancias de la policía, por la que se pedía a Telefónica el listado de los números de teléfono desde los que y a los que se habían efectuado llamadas. El Tribunal distingue entre el acceso al contenido de la comunicación, la identidad de los comunicantes y los datos de la conexión mientras la comunicación tiene lugar, y después de que haya finalizado. La garantía del art. 18.3 se extiende al primer caso; el segundo está protegido por el derecho a la intimidad; en consecuencia, cuando la intromisión se produce durante la comunicación, requiere una resolución judicial expresa, un Auto. En el otro caso, el art. 18.1 CE no requiere autorización judicial, por lo que admite restricciones excepcionales y mínimas practicadas por la policía siempre que sean proporcionadas al fin perseguido. El Tribunal entendió que una Providencia no es resolución suficiente ni idónea para limitar derechos fundamentales, pero como se trataba de un listado de teléfonos y no de una interceptación de una comunicación telefónica, la Providencia es suficiente.

Sobre el ejercicio de los cargos públicos representativos, en la STC 64/2002 se rechazó el recurso de amparo presentado contra la resolución de la Mesa del Congreso que denegó la constitución de grupo parlamentario a los Diputados elegidos en las listas del Bloque Nacionalista Galego, pues pretendían formarlo con Diputados elegidos en otras listas electorales que a su vez habían dado lugar a sus propios Grupos. Según el Tribunal, no cabe que el porcentaje de votos o el respaldo electoral obtenido por las candidaturas presentadas por una formación política sea utilizado o invocado para constituir un Grupo Parlamentario diferente al de éstos.

Por su parte, la STC 196/2002 estima el recurso de amparo interpuesto por el representante de un partido que no obtuvo espacios electorales al no solicitarlos en tiempo y forma, y que fue condenado por la comisión del delito electoral contemplado en el art. 144.1b) LOREG (actos electorales efectuados fuera del tiempo o los espacios autorizados). En este caso, el recurrente había convocado y llevado a cabo dos mítines: el primero con autorización del Ayuntamiento, que lo comunicó a la Junta Electoral de Zona que no se pronunció; el segundo, celebrado en un olivar cercano a una vía pública, se celebró en contra de la denegación acordada por la Junta Electoral. Para el Tribunal, en el primer caso la deficiencia en la actuación administrativa entre el Ayuntamiento y la Junta. Electoral no podía perjudicar al recurrente, quien, además, obraba con la confianza derivada de la autorización municipal y el silencio de la Junta Electoral; en el segundo caso, se rea- 
lizó una interpretación extensiva in malam partem, ya que el juez consideró que una reunión en las inmediaciones de un lugar de tránsito público es equiparable a una reunión celebrada en el propio lugar de tránsito público.

El Tribunal Supremo, en la Sentencia de 13 de septiembre de

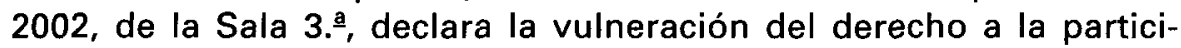
pación política de dos concejales que fueron excluidos de la votación de una moción de censura contra el alcalde, y en la Sentencia de 17 de diciembre de 2001, de la Sala 3. ${ }^{\text {a }}$, considera que el retraso reiterado en el envío de las actas de la comisión de gobierno a los concejales es constitutivo de lesión del derecho a la participación política

A propósito de la tutela judicial efectiva, en la STC 70/2002 el Tribunal se reitera en su jurisprudencia sobre la doble instancia penal y afirma que el Pacto de Nueva York no impone recursos inexistentes en nuestro orden procesal, a pesar de que el recurrente esgrimió un Dictámen del Comité de Derechos Humanos de la ONU en el que se condena a España justamente por no respetar el derecho a la doble instancia penal. El Tribunal niega toda relevancia y efectos jurídico-jurisdiccionales a estos Dictámenes.

En la STC 167/2002 se hace uso expreso del art. 13 LOTC para cambiar la doctrina sobre el alcance revisor de las apelaciones penales. En lo sucesivo, en casos de apelación contra sentencias absolutorias, cuando la apelación impugna la valoración de la prueba por el Juez de instancia, la Audiencia no puede revisar esa valoración, si no se ha pedido y practicado nueva prueba en segunda instancia cuando verse sobre pruebas cuya naturaleza exijan inmediación y contradicción en la práctica.

La STC 182/2002 afirma que se lesiona el derecho de acceso al proceso si, denegada una solicitud de beneficio de justicia gratuita por insostenibilidad de la pretensión, se procede a la inadmisión a limine del recurso sin antes ofrecer a la parte la posibilidad de seguir adelante con Abogado y Procurador propios.

En la STC 221/2002 analiza el "caso de la niña de Benamaurel», que estaba en régimen de acogimiento preadoptivo cuando la Audiencia Provincial confirmó la nulidad del expediente de desamparo. El Juez de instancia ejecutó la orden de reinserción progresiva de la menor, que había sido adoptada, en su grupo familiar de origen. Tras comprobar el fracaso de la reinserción, y a la vista de lo solicitado por la Comunidad Autónoma, el Fiscal y los acogedores, el Juez resolvió que su Sentencia (confirmada por la Audiencia) era de impo- 
sible cumplimiento en sus propios términos, por lo que acordó una ejecución sustitutoria consistente en una indemnización. Asimismo, ante el cambio de circunstancias, acordó autorizar un nuevo acogimiento en favor de la familia que inicialmente la tuvo a su cargo tras el expediente de desamparo. Recurrida dicha resolución por la familia de origen, la Audiencia rechazó dar audiencia a la menor $y$, al considerar que permanecían las mismas circunstancias que motivaron la nulidad del expediente y la reinserción en su familia de origen, anuló las resoluciones del Juez y ordenó su inmediata devolución a la familia de origen. A juicio del Tribunal, la negativa a dar audiencia a la menor y la falta de toda motivación sobre las razones por las que a su juicio no se dio el cambio de circunstancias aludido, llevan a estimar el amparo.

El Tribunal avala la legitimación de los guardadores de hecho para acudir en amparo incluso en los casos en los que no hayan sido parte en el proceso ordinario o cuando no les era exigible haberlo sido.

En materia de legalidad sancionadora, la Sentencia del Supremo de 16 de noviembre de 2001, de la Sala 3. ${ }^{\text {a }}$, considera inconstitucional una ordenanza municipal que tipifica como infracción la carencia de billete de estacionamiento.

En lo que a la protección del patrimonio se refiere, la Sentencia

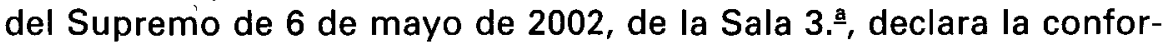
midad a derecho de la negativa de exportación de una obra pictórica integrante del patrimonio histórico. 